\title{
Editorial
}

\section{Education for information goes electronic}

More and more journals are appearing in electronic versions available via the Web, facilitating fast and easy access to their content. The editors and publishers of Education for Information are now pleased to announce that this journal has joined the digital invasion.

Readers can access Education for Information from the publisher's web site (http://www.iospress.nl). Beginning with the December 1998 issue (Volume 16, Number 4), the contents of Education for Information can easily be reviewed from this site. Titles, authors (with affiliations) and abstracts of all articles are available. Although the full text of the article is not included, it can be purchased for a modest fee. A free sample copy of an issue also can be requested. It is free to register for site access, and this enables users to customize the home page by displaying a list of their favorite IOS Press publications (hopefully including Education for Information!). Users can also be alerted by email to the appearance of a new issue as soon as it is online (and in advance of the printed copy's arrival through the post). Finally, they can search the content for individual subjects.

It should also be emphasized that prospective authors are invited to submit copy in electronic format as an email attachment (preferably as a Word file). In such cases the "manuscript" in all probability will be handled editorially without ever appearing on paper - editorial processing, refereeing, communications with the author, final editing and submission to IOS Press all have been accelerated thanks to ICT.

Despite such developments, for the foreseeable future Education for Information will continue to appear in its traditional print form as well as electronically, seeking to serve those interested in education and training for information professionals and users.

Andrew Large

Editor 